\title{
HISTÓRIA E CONTEXTUALIZAÇÃO NO ENSINO DE ESTEREOQUÍMICA: Uma Proposta de Abordagem Para o Ensino Médio
}

\author{
Daniele Trajano Raupp ${ }^{1}$ \\ Tania Renata Prochnow ${ }^{2}$ \\ José Cláudio Del Pino 3
}

\begin{abstract}
RESUMO
Os desafios do ensino de estereoquímica têm sido objeto de estudo há décadas. A resolução de problemas, em âmbito tridimensional, é considerada umas das fontes de dificuldade. Além disso, a falta de motivação para a aprendizagem é uma barreira no ensino de Química. Buscando uma estratégia de ensino baseada na Teoria dos Campos Conceituais, a qual pressupõe que um conceito se torna significativo para o sujeito a partir de uma variedade de situações, realizou-se um estudo de caso exploratório com estudantes de Ensino Médio Técnico em Química. O estudo é um recorte de uma pesquisa de Doutorado e aborda, exclusivamente, a investigação sobre a evolução dos estudantes acerca dos aspectos históricos e contextuais da estereoquímica com a aplicação de uma unidade de ensino. Utilizando o método misto e análise de conteúdo, constatou-se, por meio de pré e pós-testes, que o uso de unidade de ensino, previamente validada por professores de Química, possibilitou aos estudantes a compreensão de uma variedade de situações, aumentando seu repertório de conhecimento, o que torna o conceito significativo. Essa significação pode motivar a aprendizagem, colaborando para o domínio do campo da estereoquímica e para superação das dificuldades exclusivas da área.
\end{abstract}

Palavras-chave: História da ciência. Estereoquímica. Contextualização. Teoria dos Campos Conceituais.

\section{HISTORY AND CONTEXTUALIZATION IN ESTEREOCHEMICAL EDUCATION: A PROPOSED APPROACH TO HIGH SCHOOL}

\begin{abstract}
The challenges of teaching stereochemistry have been studied for decades. Problem solving, on a three-dimensional level, is considered as one of the sources of difficulty. In addition, the lack of motivation for learning is a barrier in teaching chemistry. Searching for a teaching strategy based on Conceptual Field Theory, which presupposes that a concept becomes significant for the subject from a variety of situations, an exploratory case study was carried out with students of Technical High School in Chemistry. The study is a cut from a doctoral research and exclusively addresses research on the evolution of students about the historical and contextual aspects of stereochemistry with the application of a teaching unit. Using the mixed method and content analysis, it was verified, through pre and post tests, that the use of a teaching unit, previously validated by chemistry teachers, enabled the students to understand a variety of situations, increasing their repertoire of knowledge, which makes the concept meaningful. This significance can motivate learning by collaborating in the field of stereochemistry and overcoming the unique difficulties of the area.
\end{abstract}

Keywords: History of science. Stereochemistry. Contextualization. Conceptual Field Theory.

Recebido em: 1이릴

Aceito em: 8/5/2019

\footnotetext{
Departamento de Química Orgânica, Universidade Federal do Rio Grande do Sul (UFRGS), Porto Alegre, RS, Brasil. http://lattes.cnpq. br/2620530116584214.https://orcid.org/0000-0003-2314-5352. daniele.raupp@ufrgs.br

2 Programa de Pós-Graduação em Ensino de Ciências e Matemática, Universidade Luterana do Brasil (Ulbra). Canoas, RS, Brasil. http://lattes. cnpq.br/1098749425569199. https://orcid.org/0000-0003-1173-3384. tania.pro@gmail.com

3 Programa de Pós-Graduação em Educação em Ciência Química da Vida e Saúde, Universidade Federal do Rio Grande do Sul (UFRGS), Porto Alegre, RS, Brasil. http://lattes.cnpq.br/2152799270731771. https://orcid.org/0000-0002-8321-9774. delpinojc@yahoo.com.br
} 
O ensino de estereoquímica e seus desafios têm sido discutidos há décadas, com a complexidade, na resolução de problemas, no plano tridimensional, sendo considerada uma das principais fontes de dificuldades de aprendizagem (FROMM, 1945; SHINE, 1957; EVANS, 1963; HABRAKEN, 1996; WU; SHAH, 2004). Além disso, existe uma outra barreira a ser transposta na sala de aula de Química no Ensino Médio: a motivação do estudante para a aprendizagem (CARDOSO; COLINVAUX, 2000). De acordo com Pozo (2002, p. 146), "a motivação pode ser considerada como um requisito, uma condição prévia da aprendizagem". Quando o estudante tem interesse por determinada área, esse interesse "o impulsiona a se aprofundar nela e a vencer os obstáculos que possam ir se apresentando ao longo do processo de aprendizagem" (TAPIA; FITA, 1999, p. 78). Alguns estudantes adquirem certa resistência à Química devido ao foco em memorizar símbolos, nomes, propriedades, fórmulas e tabelas (BERNARDELLI, 2014; CHASSOT, 2000). Dessa forma, acaba tornando-se rotineira a não compreensão de fenômenos que não são relacionados ao seu cotidiano (GABEL, 1993). Tal fato configura-se com uma aprendizagem mecânica, na qual o aluno tenta aprender sem entender do que se trata ou compreender o significado do porquê.

Não só o problema do aprendizado, mas também a questão da motivação pode ser compreendida sob a ótica das teorias cognitivistas, devido à forte relação estabelecida entre o aprendizado e o contexto. Nesse estudo exploratório utilizou-se como alicerce a Teoria dos Campos Conceituais do psicólogo e matemático francês Gerard Vergnaud. Para Vergnaud (1982), um conceito só tem sentido em um determinado contexto. Essa teoria é uma poderosa ferramenta na construção de planejamentos didáticos (CARVALHO JUNIOR; AGUIAR JUNIOR, 2008) e atribui ao professor o papel de promover oportunidades, para que os estudantes superem suas dificuldades, buscando entender melhor quais são os problemas de desenvolvimento específicos de um determinado campo de conhecimento, permitindo prever formas mais eficientes de trabaIhar os conteúdos (VERGNAUD, 1982, 1994, 1996a). A eficiência no ensino, sob o olhar dessa teoria cognitivista, significa a escolha de situações-problema que efetivamente promovam o desenvolvimento cognitivo do estudante dentro do campo conceitual específico. Este trabalho utiliza interpretação do termo contextualização de acordo com Rebello et al. (2007), alicerçada na Teoria dos Campos Conceituais, de Gerard Vergnaud (1982): a contextualização é fator determinante, condição para aprendizagem e não apenas um fator motivacional. Assim, pode-se interpretar a contextualização como uso das situações que dão sentido ao conceito e que envolvem, além da questão de como o conhecimento científico é encontrado em nossa vida diária, a contextualização histórica para enfatizar a ciência como um processo de construção humana e social.

Os elementos, anteriormente destacados, conduziram os pesquisadores ao desenvolvimento de uma estratégia didática que objetiva favorecer a aprendizagem da estereoquímica no Ensino Médio Técnico em Química. Torna-se necessário destacar que, neste artigo, traz-se um recorte de uma pesquisa cuja proposta é abordar os resultados relacionados apenas às esferas histórica e contextual que se acredita serem fundamentais para a motivação na aprendizagem do campo conceitual, uma vez que estariam relacionadas às situações que dão sentido ao conceito. O foco, portanto, está nas situações de aprendizagem que podem ser utilizadas em sala de aula para tornar eficien- 
te o domínio do campo conceitual a partir da contextualização como fator-chave para a aprendizagem. Dessa forma, o objetivo geral é investigar a evolução dos estudantes (utilizando pré e pós-testes) acerca dos aspectos históricos e contextuais da estereoquímica com a aplicação de uma unidade de ensino.

Enfatiza-se, previamente, que a teoria de Vergnaud trata a construção conceitual dentro do domínio do tripleto S-I-R (Situação, Invariantes operatórios e Representações). Assim, a perspectiva teórica de Vergnaud não se restringe apenas à análise de situações. Em suma, essa é a motivação pela qual não se estudam situações ou conceitos de forma isolada, mas, sim, campos conceituais. Além disso, o domínio de um campo conceitual é algo progressivo, que demanda o uso de uma variedade de conceitos, de situações, de esquemas e de representações simbólicas, todos em estreita conexão (VERGNAUD, 1996a). As questões relacionadas ao domínio dos conceitos científicos, representações e invariantes operatórios não estão contempladas nesse escopo.

\section{CONTEXTUALIZAÇÃO E HISTORICIDADE NO ENSINO DE QUÍMICA}

Analisando-se a origem do termo contextualização, do latim "contextus", a palavra contexto significa "coerência", "conexão", "relacionamento". Dessa forma, o uso do "contexto" objetiva descrever as circunstâncias que dão sentido às palavras, frases e sentenças (GILBERT, 2005; SILVA SOUZA; LEITE, 2016). O termo contextualização no ensino possui diversas definições. Wartha, Silva e Bejarano (2013) comentam que contextualização é um termo relativamente novo na língua portuguesa e que começou a ser utilizado a partir da promulgação dos Parâmetros Curriculares Nacionais em substituição ao termo cotidiano. Para alguns professores, contextualizar significa motivar os estudantes e isso pode ser usado para tornar questões científicas relevantes para eles, tendo impacto positivo para a motivação e aprendizagem (REBELLO et al., 2007).

Essa interpretação vem ao encontro da proposta para ensinar Química, baseada no conceito de cotidiano de Heller (1989): "buscar extrair conhecimentos extraordinários do ordinário", propondo, assim, uma análise de como o conhecimento científico, apresentado em sala de aula, é encontrado em nossa vida diária. A contextualização, de acordo com González (2004), pode ser abordada com distintos enfoques, sendo proposta pelo autor a utilização de três dimensões: histórica, metodológica e socioambiental, descritas a seguir:

a. contextualização histórica: com a finalidade de mostrar como e por que surgem as ideias e teorias, como uma conquista humana, obtida dos esforços de pessoas que viveram em um momento histórico, participando de forma significativa em muitos casos;

b. contextualização metodológica: uma abordagem sobre como a ciência é construída em oposição à visão dogmática e de senso comum muitas vezes oferecida a partir de uma ciência acabada e pré-fabricada, em que o estudante é um mero receptor e consumidor;

c. contextualização socioambiental: caracteriza-se como um modo de ver a utilidade da ciência em nosso entorno e no modo de interagir com o mundo. 
Com essa abordagem, a contextualização, que é entendida como estratégia para facilitar a aprendizagem (SANTOS; MORTIMER; 1999), ganha um sentido mais amplo e pode tornar mais clara a elaboração de uma estratégia de ensino. Uma outra interpretação estaria relacionada com a tentativa de exemplificar, de forma superficial, fatos ligados à vivência do estudante, ficando meramente no comentário do fato ou usar a contextualização apenas como uma introdução ao conteúdo químico para "dourar a pílula" (SILVA; SILVA, 2007).

A discussão sobre ensinar conceitos científicos, de forma contextualizada, não é uma novidade no Ensino de Ciências. Por influência dos positivistas, no ano de 1890, ciências como Matemática, Astronomia, Física e Química foram incluídas na Educação Básica brasileira (DA ROSA; DA ROSA, 2012). Somente com a reforma Francisco Campos, em 1931, porém, a Química passou a estar oficialmente presente nos currículos brasileiros, tendo como objetivo proporcionar aos estudantes o conhecimento da Química "orientando-o por um raciocínio lógico e científico de valor educativo e coordenando-o, pelo interesse imediato da utilidade, com as aplicações da vida cotidiana" (BRASIL, 1931, p. 70). Essa reforma já sinalizava a importância de articular o ensino de Química com o cotidiano (BRASIL, 2001). Nos Parâmetros Curriculares Nacionais encontra-se a afirmação de que a abordagem da Química na escola, "embora às vezes 'maquiada' com uma aparência de modernidade, a essência permanece a mesma, priorizando-se as informações desligadas da realidade vivida pelos estudantes e pelos professores" (BRASIL, 1999, p. 30). Essa realidade maquiada e desconexa também é ressaltada por Lima et al. (2000, p. 26) ao afirmarem que "o ensino de Química, muitas vezes, tem-se resumido a cálculos matemáticos e memorização de fórmulas e nomenclaturas de compostos [...]". Mais recentemente o texto das Diretrizes Curriculares Nacionais deixa clara a necessidade de "minimizar o atual distanciamento existente entre as diretrizes e a sala de aula" (BRASIL, 2013, p. 11), uma vez que o tema contextualização é discutido há décadas, mas, na realidade, não é observado como uma prática docente.

Considerando essas ponderações nos documentos oficiais do Ministério da Educação, percebe-se a existência de orientações para a utilização de uma abordagem que contemple não só aspectos relacionados ao contexto dos estudantes, como também aspectos históricos. A relevância do conteúdo histórico foi claramente abordada nas DCNs (Diretrizes Curriculares Nacionais da Educação Básica), ao citar que a escola deve conseguir ensinar a compreender o que é ciência, qual a sua história e a quem ela se destina (BRASIL, 2013, p. 33). Mais recentemente, a Base Nacional Comum Curricular (BNCC) destaca que: a contextualização social, histórica e cultural da ciência e da tecnologia é fundamental para que elas sejam compreendidas como empreendimentos humanos e sociais (BRASIL, 2018, p. 549). Embora seja reconhecida a importância da compreensão da ciência como sendo um processo de construção social, na prática isso não ocorre nas salas de aula ou ocorre de forma superficial.

Essa superficialidade reside tanto na questão contextual quanto histórica e um dos motivos pode estar associado ao fato de que, no Ensino Médio, os professores dependem de livros didáticos para selecionar o conteúdo histórico, a fim de incluir em suas aulas de ciências (LEITE, 2002). A presença do livro didático, como orientador dos 
trabalhos em sala de aula, é uma realidade (LOGUERCIO; DEL PINO, 1995, p. 1) há décadas e ainda mais a partir de 1985, quando foi criado o PNLD - Programa Nacional do Livro Didático.

Em alguns livros didáticos, utilizados no Ensino Médio, a contextualização é tratada como uma mera informação adicional ou uma "curiosidade". Desse modo, os estudantes podem estar recebendo a mensagem de que nomes, fórmulas e propriedades são o foco de estudo e que a compreensão dos demais aspectos é irrelevante (RAUPP; DEL PINO, 2015). Brush (2000) comenta que escritores de livros didáticos parecem não prestar atenção suficiente para a pesquisa histórica sobre a ciência. Niaz (2000) argumenta que a história da ciência é tratada nos livros didáticos de maneira inadequada. Isso ocorre não por limitações de espaço, mas por falta de conhecimento de história e filosofia da ciência. Ao investigar a inclusão de aspectos históricos em livros, alguns resultados apontam para a ausência ou para a superficialidade na abordagem (FERNANDES; PORTO, 2012; LEITE; PORTO, 2015 ).

Ainda que os professores considerem importante a contextualização no ensino, frequentemente a fazem de maneira simplista em sua prática docente (VILCHES; SOLBES, 2000; SILVA; SILVA, 2007). Mortimer, Machado e Romanelli (2000, p. 275) afirmam que: "os currículos tradicionais, ao abordarem apenas aspectos conceituais da Química, têm como pressuposto que a aprendizagem de estruturas conceituais antecede qualquer possibilidade de aplicação dos conhecimentos químicos". Outros autores parecem ter ficado presos em algumas ideias históricas, sem perceber que a ciência tem evoluído e que algumas analogias (históricas), que eles estão usando para apresentar determinados conteúdos, já foram abandonadas por cientistas no passado (STOCKLMAYER; TREAGUST, 1994). Os próprios professores raramente trabalham esse tipo de conhecimento em suas aulas devido às dificuldades em fazê-lo (ORTIZ; PASSOS; DA SILVA, 2016).

Em contraposição aos currículos tradicionais, têm-se teorias cognitivistas que defendem que a relação com o cotidiano é um fator determinante para a aprendizagem (BARRERA, 2010). Pesquisas atuais na área sustentam que a apresentação historicamente organizada do conteúdo seria a maneira correta de dar aos alunos uma ideia adequada sobre a natureza da ciência, a forma como ela se desenvolve e de como os cientistas trabalham, apresentando evolução histórica real de alguns dos conceitos de ciência ou princípios que ela inclui, de modo que os estudantes possam adquirir uma sensação de como a ciência evolui sob a influência de fatores internos e externos (LEITE, 2002). Ideia que vem ao encontro de Schmiedecke e Porto (2015), que destacam a possibilidade de discussão sobre a natureza da ciência como uma das razões principais para a abordagem histórica da ciência no ensino, desde que essa discussão tenha objetivos modestos, com o foco em desenvolver uma visão acerca da complexidade da ciência, uma vez que a complexidade das reflexões, trazidas pelos historiadores, filósofos e sociólogos da ciência não faz parte do escopo do ensino de ciências na educação básica (MATTHEWS, 1995). Tanto essa noção sobre a história quanto a compreensão da aplicação no contexto podem contribuir para o domínio do campo conceitual da estereoquímica, uma vez que a contextualização é um fator determinante para aprendizagem. 


\section{A TEORIA DOS CAMPOS CONCEITUAIS}

A Teoria dos Campos Conceituais (TCC) foi desenvolvida na década de 70 do século 20 pelo psicólogo e matemático francês Gerard Vergnaud e busca entender melhor quais são os problemas de desenvolvimento específicos de um determinado campo de conhecimento. Postula que a essência do desenvolvimento cognitivo é a conceitualização (VERGNAUD, 1996a). O significado de conceitualização, nessa perspectiva, é compreendido como o processo de formação ou construção de conceitos, processo que é considerado a pedra angular da cognição (VERGNAUD, 1996b). No progressivo domínio de um campo conceitual pelos estudantes, para o professor a tarefa mais difícil é a de prover oportunidades aos estudantes para que desenvolvam seus esquemas e superem suas dificuldades. Uma das particularidades marcantes, nesse aporte teórico, é que não se veem conceitos como entidades isoladas, mas entrelaçadas entre si. Campo Conceitual é definido como um conjunto de problemas, situações, conceitos, relações, estruturas, conteúdos e operações de pensamento, conectados uns aos outros e, provavelmente, entrelaçados durante o processo de aquisição (VERGNAUD, 1982).

Essa é a motivação pela qual não se estudam situações isoladas ou conceitos isolados, mas, sim, Campos Conceituais. O domínio de um campo conceitual é algo progressivo e demanda o uso de uma variedade de conceitos, de esquemas e de representações simbólicas, todos em estreita conexão (VERGNAUD, 1996a; ARICAN, 2018). O conhecimento é construído pelas interações entre o aprendiz e as situações vivenciadas por ele; assim, a aprendizagem acontece à medida que os conceitos se tornam, ao longo do tempo, conceitos científicos reais (DE ANDRADE; HONÓRIO; BUENO FILHO, 2017).

Para o domínio do campo da estereoquímica, por exemplo, antes de compreender como uma mesma fórmula molecular dá origem a diferentes compostos, é preciso entender uma rede de conceitos - como átomo, molécula, ligações químicas (simples, duplas e triplas) e representações, como as de fórmulas químicas, fórmula estrutural plana e espacial, quiralidade, conformação, configuração, etc. - para somente então compreender o conceito de estereoquímica como um todo. Consequentemente o campo conceitual, que engloba o conceito de estereoquímica, é delimitado pelos conceitos, situações e representações pertinentes à área (RAUPP; DEL PINO, 2015). Assim sendo, um conceito é considerado tríade e pode ser representado da seguinte forma: $\mathrm{C}=\mathrm{SIR}$ (Conceito = Situação, Invariantes operatórios e Representações simbólicas). Resumidamente podemos considerar as seguintes considerações sobre cada um desses elementos:

a) Situação ou referente é o conjunto das situações que dá sentido ao conceito ou às situações para as quais o conceito é útil e significativo (VERGNAUD et al., 1993, p. 8; PANTOJA, MOREIRA, 2017) e o sentido dos conceitos está na situação em si. Um conceito torna-se significativo mediante uma variedade de situações e de diferentes aspectos de um mesmo conceito (VERGNAUD, 1994).

b) Invariantes operatórios podem estar associados ao conceito ou ao conjunto de invariantes que podem ser reconhecidos e usados pelos sujeitos para analisar e dominar as situações (PANTOJA, MOREIRA, 2017). São componentes essenciais dos esquemas (VERGNAUD, 1994) e são classificados em dois tipos: conceito-em-ação e teorema- 
-em-ação, que designam os conhecimentos contidos nos esquemas. Os conceitos e teoremas-em-ação são os conceitos ou teoremas específicos, mobilizados para resolução de uma dada situação, ou seja, dentro de uma vasta gama de conceitos e teoremas que podem estar disponíveis no repertório dos estudantes. São colocados em ação apenas alguns que podem, inclusive, ser adequados ou inadequados para uma dada classe de situações (VERGNAUD, 1998).

c) Representação: é "o conjunto das formas de linguagem (ou não) que permitem representar simbolicamente o conceito, suas propriedades, as situações e os procedimentos de tratamento". (VERGNAUD et al., 1993 , p. 8). Esse conjunto de representações simbólicas pode conter linguagem natural, gráficos e diagramas e sentenças formais que podem ser usadas para indicar e representar os invariantes e, consequentemente, representar as situações e os procedimentos para lidar com elas (MOREIRA, 2002).

Toda vez que um sujeito resolve um problema significa que ele desenvolveu um eficiente esquema para tratá-lo, desaparecendo, assim, o caráter problemático referente a essa situação. Desse modo, da próxima vez que o sujeito estiver diante de um novo problema, será capaz de reconhecê-lo e tratá-lo com seus esquemas, ou considerá-lo como um novo problema. Por isso, a conceitualização é considerada um processo cíclico e dialético (GASTALDO, 2007).

\section{As situações no campo conceitual da estereoquímica}

São as situações que facilitam o processo de conceitualização e dão sentido ao conceito (VERGNAUD, 1994), porque "quando um estudante se depara com situações que dão sentido ao conceito, essa informação entra em interação com a estrutura dos conhecimentos-em-ação dos esquemas que cada estudante dispõe" (DE OLIVEIRA GRINGS; MOREIRA; CABALLERO, 2007, p. 464). A noção de que um conceito torna-se significativo para o indivíduo por meio de uma variedade de situações é fundamental nesse aporte (VERGNAUD, 1994). Assim, estereoquímica é um tema rico no que diz respeito às possibilidades de contextualização histórica, metodológica e socioambiental (RAUPP; DEL PINO, 2015). No que se refere à contextualização, nessa área, pode-se inferir que há três elementos básicos a serem abordados com o objetivo de dar sentido ao conceito, conforme Figura 1.

Figura 1 - História, contexto e conceitos científicos interligados

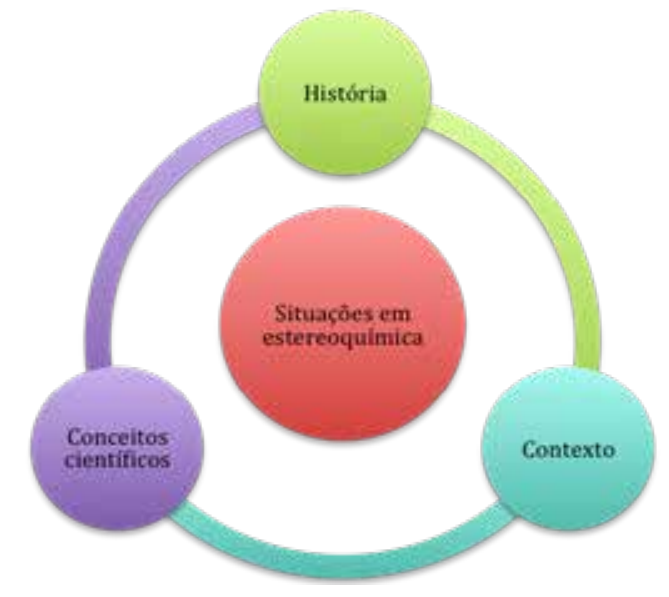

Fonte: Elaborada pelos autores (2019).

Contexto \& Educação

Editora Unijuí •ISSN 2179-1309 • Ano 35 • no 112 • Set./Dez. 2020 
a) Conceitos científicos: para reconhecer o fenômeno do isomerismo, um dos conceitos fundamentais da Química Orgânica é a base do estudo da química estrutural (ESTEBAN, 2008), tarefa essa que envolve a compreensão de fórmulas moleculares e estruturais, estruturas bi e tridimensionais, projeções de Fischer, nomenclatura cis, trans; $E, Z ; R, S$; classificações dos diferentes isômeros como estereoisômeros, enantiômeros, etc.

b) Contexto: envolve a compreensão da utilidade da ciência utilizando situações do cotidiano ou possíveis de serem contextualizadas. Um exemplo é o aspartame, um adoçante sintético não calórico, utilizado para substituir o açúcar comum, com uso largamente difundido no Brasil e no mundo, que possui dois isômeros: um tem sabor doce, enquanto outro epímero tem sabor amargo (COELHO, 2001). Outro exemplo está no ácido láctico: o esteroisômero ácido láctico levógiro é produzido industrialmente por meio da fermentação bacteriana da lactose e empregado na neutralização da cal, no curtimento de couros e na indústria alimentícia, como acidulante. Já o ácido láctico dextrógiro é produzido no próprio organismo humano. Quando se metaboliza glicose, pela atividade muscular anaeróbica, o ácido láctico é gerado nos músculos e depois oxidado totalmente a $\mathrm{CO}_{2}$ e $\mathrm{H}_{2} \mathrm{O}$ (LEHNINGER; NELSON, 1995). Durante as últimas seis décadas a maioria das descobertas em Química foi relacionada a aspectos estruturais, o que inclui estudos de aspectos químicos e estereoquímicos, novas metodologias para determinação de estrutura, estrutura de novos materiais e síntese orgânica (HARGITTAI; HARGITTAI, 2012), além do exemplo de biomoléculas como aminoácidos, carboidratos, ácidos nucleicos e ácidos graxos e, até mesmo, os biopolímeros (CHENG et al., 2017).

c) História: situações que envolvam a história do tema, por exemplo, a constatação de dois cientistas que, por volta de 1820, trabalhando separadamente, em seus respectivos laboratórios, sintetizaram dois compostos com propriedades distintas, mas que, surpreendentemente, apresentaram a mesma constituição química. Justus von Liebig, químico e inventor alemão, trabalhava em Paris, no laboratório de seu orientador, Louis Joseph Gay-Lussac, físico e químico francês, quando sintetizou um reagente explosivo que ele determinou ser fulminato de prata, cuja fórmula molecular é AgCNO. Simultaneamente Friedrich Wöhler, pedagogo e químico alemão, orientado pelo químico sueco Jöns Jacob Berzelius (Figura 2), sintetizou o cianato de prata (AgOCN) em seu laboratório em Estocolmo (KURZER, 2000). Ou ainda as desavenças no início do desenvolvimento da área de Química Orgânica, quando a ideia de que os átomos de uma molécula se organizavam no espaço era considerado um devaneio. Em 1877, um dos mais eminentes químicos orgânicos da época, Hermann Kolbe, da Universidade de Leipzig, Alemanha, criticou fortemente as ideias de van't Hoff sobre o arranjo espacial dos átomos. Kolbe escreveu uma carta, afirmando que essa ideia não passava de uma fantasia infantil (GRAHAM SOLOMONS; FRYHLE, 2001).

Todas as situações propostas no estudo desse campo podem ser abordadas de modo a integrar os conceitos científicos com a história e o contexto. Julga-se fundamental a construção de uma estratégia que considere o diálogo entre história e contexto como um fator não só motivacional, mas também importante para a aquisição de conhecimento (RAUPP; DEL PINO, 2015). 


\section{METODOLOGIA}

A pesquisa foi realizada com métodos mistos, pois se trata de uma abordagem com foco nas questões investigativas relacionadas à compreensão do contexto analisado (DAL-FARRA, FETTERS, 2017). Caracteriza-se pela associação de elementos qualitativos e quantitativos que "possibilita ampliar a obtenção de resultados em abordagens investigativas, proporcionando ganhos relevantes para as pesquisas complexas realizadas no campo da educação" (DAL-FARRA, LOPES, 2013, p. 67). Trata-se de um estudo de caso exploratório, pois essa é uma fase preliminar que tem como finalidade proporcionar mais informações sobre o assunto, utilizando-se o estudo aprofundado de um grupo de estudantes, de um curso técnico em Química (PRODANOV; FREITAS, 2013). Os procedimentos metodológicos utilizados na pesquisa, foram organizados em cinco diferentes etapas (Figura 2).

Figura 2 - Etapas da metodologia

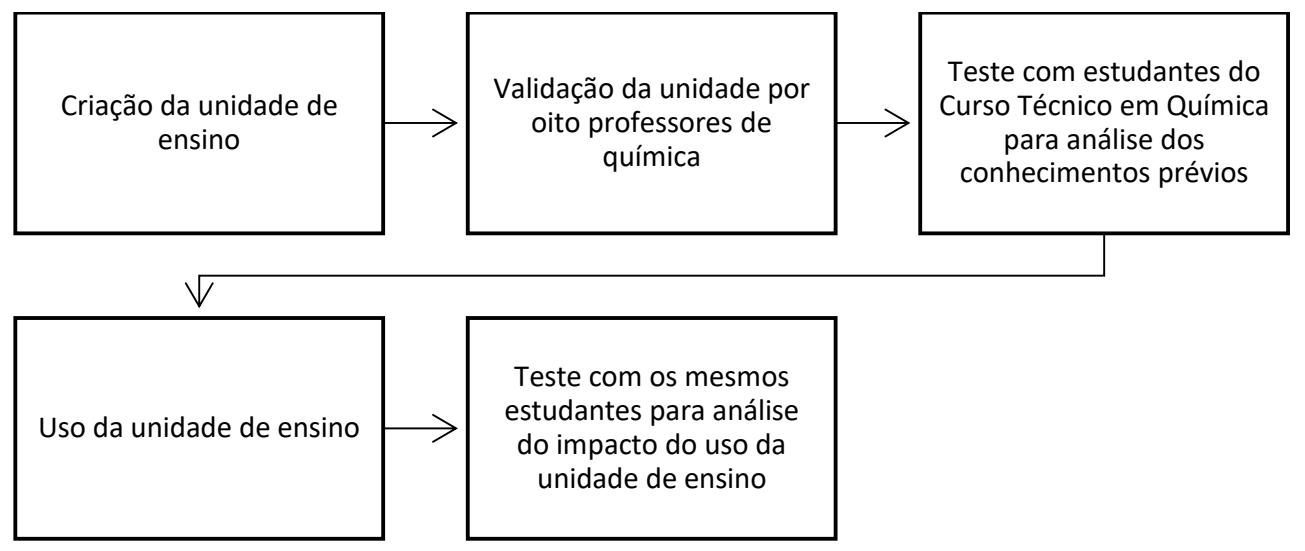

Fonte: Elaborada pelos autores (2019).

Buscando-se uma forma mais eficiente de trabalhar o conteúdo, uma unidade de ensino foi produzida. Utilizou-se o modelo de sequência didática, que é um modo de o professor organizar as atividades de ensino em função de núcleos temáticos e procedimentais (DE ARAÚJO, 2013). Essa unidade foi submetida à avaliação de oito professores e investigadores da área de Química e Educação em Química. Essa validação foi solicitada via e-mail, contento, em seus anexos, uma cópia da unidade e um guia com os tópicos a serem avaliados como: uso de conceitos, aspectos históricos e contextuais abordados na unidade. Os oito participantes, que avaliaram a unidade, atuavam nos níveis de Ensino Médio (dois professores), Ensino Médio Técnico em Química (três professores) e Ensino Superior (três professores), cumprindo, dessa forma, os objetivos específicos: "desenvolver uma unidade de ensino baseada em uma estratégia didática que favoreça aprendizagem do campo conceitual" e "validar a unidade de ensino por professores de Química de diferentes níveis de ensino". Após a validação da unidade projetou-se atingir os demais objetivos específicos: "investigar a compreensão de estudantes de Ensino Médio Técnico em Química sobre o campo conceitual da estereoquímica para diagnosticar o nível de compreensão histórica e contextual", e "verificar o aprimoramento dessa compreensão após uso da unidade de ensino". A unidade, organizada em seis temáticas, tem a estrutura apresentada na Figura 3: 
Figura 3 - Estrutura da unidade de ensino criada

\begin{tabular}{|c|c|}
\hline 1 INTRODUÇÄO & Questరెes para discussão \\
\hline $\begin{array}{l}\text { 2. CONCEITOS FUNDAMENTAIS } \\
\text { 2.1 Estrutura molecular } \\
2.3 \text { Classificação dos estereoisômeros } \\
\text { 2.4 Nomenclatura de diasteroisómeros } \\
\text { 2.5 Nomenclatura de enantiômeros } \\
\text { Questöes para discussäo }\end{array}$ & $\begin{array}{l}\text { 5. A ESTEREOQUIMICA DOS FARMACOS } \\
5.1 \text { O caso da Talidomida } \\
5.2 \text { A estereoquimica dos anestésicos } \\
\text { 5. } 3 \text { O poder do Resveratrol contra o envellecimento } \\
\text { 5.4 Racematos e enantiómeros puros } \\
\text { Questöes para discussajo }\end{array}$ \\
\hline $\begin{array}{l}3 \text { UMAA BREVE HISTORIA DA ESTEREOQUTMCA } \\
\text { Questöes para diseussão }\end{array}$ & $\begin{array}{l}6 \text { ESTRUTURA 3D E SUA RELAÇÃO COM AS PROPRIEDADES } \\
\text { DAS SUBSTANNCLAS }\end{array}$ \\
\hline $\begin{array}{l}\text { 4. A ESTEREOQUIMICA NO NOSSO COTIDLANO } \\
\text { 4.1 Organismos vivos e a quiralidade } \\
\text { 4.2 Os sabores e aromas dos isômeros } \\
\text { 4.3 A estereoisomeria relacionada à visão } \\
\text { 4.5 Os ácidos orgânicos e suas distintas propriedades }\end{array}$ & $\begin{array}{l}\text { 6.1 Software para visualizaçào de estruturas tridimensionais } \\
\text { Exercicios }\end{array}$ \\
\hline
\end{tabular}

Fonte: Elaborada pelos autores (2019).

Amostragem - Após a validação da unidade de ensino o estudo exploratório foi realizado com duas turmas de Ensino Médio, de um Curso Técnico em Química, da região metropolitana de Porto Alegre. A turma "A" possuía 28 estudantes e a turma "B" 25. A amostra, nessa etapa, é classificada como não probabilística intencional, uma vez que, das quatro turmas disponíveis, foram escolhidas as duas que tinham o mesmo professor de Química Orgânica. Ambas as turmas já haviam trabalhado com o conteúdo "Isomeria" em sala de aula. Em todas as etapas os estudantes participaram voluntariamente da pesquisa. Para ser considerado válido, os instrumentos não poderiam estar em branco e o estudante deveria ter participado de todos os encontros ao longo das quatros semanas. No primeiro teste obteve-se um total de 49 válidos. Já no último teste foram 31 válidos, em razão dos critérios estabelecidos. E um total de 42 estudantes responderam questões baseadas na escala Likert.

A metodologia contou com três etapas, distribuídas em aulas ao longo de quatro semanas, tendo 2 períodos de 50 minutos por semana.

Semana 1 - Na primeira semana foi aplicado de um teste com cinco questões objetivas conceituais (as quais não fazem parte do escopo de análise para este artigo) e duas questões abertas sobre história e contexto.

Semana 2 - Na segunda semana os estudantes receberam uma cópia da unidade de ensino. ${ }^{4}$ Após abordagem introdutória e uma sucinta explanação sobre conceitos fundamentais da área, foi elaborado um capítulo, narrando, resumidamente, a história da estereoquímica, abrangendo os principais avanços e os principais cientistas envolvidos na consolidação dessa área. Neste capítulo, o texto elaborado apresenta uma "linha do tempo" sobre o desenvolvimento da estereoquímica e apresenta não só dados biográficos dos cientistas envolvidos, como também, em alguns casos, comentários adicionais sobre local de trabalho, quem era seu orientador, seus parceiros de trabalho. Alguns avanços científicos são mencionados e outros são descritos em detalhes e cada cientista citado é relacionado com sua imagem em ilustração ou foto com o objetivo de personificação.

A unidade de ensino está disponível na íntegra no texto da tese. Disponível em: https://lume.ufrgs.br/handle/10183/122337 
Havia também um capítulo sobre as relações com o cotidiano, com exemplos que vão desde aromas e sabores até os exemplos mais discutidos atualmente, como é o caso da gordura trans. Para abordar o caso dos fármacos, um capítulo distinto foi criado para apresentar alguns exemplos. $\mathrm{O}$ famoso caso da Talidomida está presente, mas também há outras informações relevantes na área. Em ambos os capítulos todos os exemplos foram elaborados apresentando-se a fórmula molecular, fórmula estrutural e o respectivo nome. Nessa etapa foi feita uma sucinta explanação sobre o material e foi solicitada a leitura detalhada como tarefa, bem como a realização dos exercícios propostos. Nesse ponto cabe salientar que os alunos já haviam trabalhado todo o conteúdo relativo à isomeria, tanto constitucional quanto a estereoisomeria e que, por esse motivo específico, a unidade de ensino não foi abordada completamente em aula, em relação aos conceitos fundamentais. A atividade em aula focou na abordagem histórica e contextual do tema.

Semana 3 - Na terceira semana utilizou-se o laboratório de informática para realização da atividade, relacionada ao item 6 , com o uso do software gratuito Chemesketch da ACDLAbs (a análise dessa atividade não está incluída no escopo deste artigo).

Semana 4 - Finalmente, na quarta semana, os estudantes participaram da etapa final que consistiu em um teste, semelhante ao primeiro, com cinco questões objetivas conceituais (as quais não fazem parte do escopo de análise para este artigo) e as mesmas duas questões abertas sobre história e contexto.

A utilização de pré e pós testes iguais (ou diferentes) é tema amplamente debatido na comunidade de ensino. Usando um grupo de controle ou de comparação, esse método de coleta de dados é considerado um dos mais respeitados que pode ser usado para medir a mudança (conceitual) em indivíduos (KAPLAN, 2004). Esse tipo de instrumento de coleta é altamente considerado pela sua capacidade de comparar os resultados das mesmas pessoas ou grupos de pessoas em vários momentos. Obviamente o método possui suas limitações, uma delas o tempo disponível entre os testes (BROOKS; GERSH, 1998). Além disso, para que as comparações entre pré-teste e pós-teste sejam significativas, os integrantes devem participar do programa completo da pesquisa, do início ao fim (PRATT; MCGUIGAN; KATZEV, 2000). Outro ponto a ser observado como limitação é o viés de desvio de resposta. Bhanji et al.(2012) afirmam que, quando no pós-teste, os alunos entendem a(s) dimensão(ões) mensurada(as) eles recalibram seus critérios para respondê-lo, uma vez que os estudantes normalmente completam uma pesquisa antes da intervenção e novamente após a intervenção. Apesar das limitações, muitas pesquisas na área de ensino utilizam esse método, pois é possível medir tanto o quadro posterior a uma intervenção didática quanto as concepções que os estudantes tinham antes da intervenção.

Considerando as vantagens e limitações do método, optou-se por uma estratégia metodológica baseada no uso de pré e pós-testes iguais para todos os estudantes e, na etapa qualitativa de exploração do material, e tratamento dos dados, foram comparadas as respostas de um mesmo estudante no pré e nos pós-teste, evidenciando a diferença na explanação e/ou nos exemplos usados. Destaca-se que o objetivo do uso desse 
instrumento não é uma análise de aprendizagem do campo conceitual em si, mas, sim, uma verificação sobre o repertório de situações relacionadas à estereoquímica que o aluno é capaz de demonstrar.

Além desse teste, nessa etapa, os estudantes responderam questões baseadas na escala Likert, na qual os respondentes especificam seu nível de concordância com uma afirmação sobre a unidade de ensino, com o objetivo de avaliar a opinião sobre seu uso. Em ambos os testes os estudantes deveriam responder (além das questões relativas aos conceitos) às seguintes indagações: a) Você conhece a história do desenvolvimento da estereoquímica? Então escreva sobre essa história (fatos, descobertas, cientistas envolvidos, etc.); b) Na estereoquímica, temos inúmeros exemplos que podem ser relacionados com nosso cotidiano. Você conhece algum exemplo?

Os dados coletados foram examinados pelo método de análise de conteúdo. Esse método foi escolhido por ser um procedimento clássico para analisar o material textual, buscando-se "compreender as características, estruturas ou modelos que estão por trás dos fragmentos de mensagens tornados em consideração" (CÂMARA, 2013, p. 182), possibilitando identificar percepções do sujeito por meio das etapas de pré-análise, exploração do material e tratamento dos resultados - a inferência e a interpretação (BARDIN, 1977).

\section{RESULTADOS E DISCUSSÃO}

Para a primeira questão, "Você conhece a história do desenvolvimento da estereoquímica? Então escreva sobre essa história (fatos, descobertas, cientistas envolvidos etc.)", os resultados obtidos foram categorizados da seguinte forma: considerou-se como "Sim" estudantes que comentaram algum fato relacionado ao desenvolvimento histórico da área. Já os demais, que não comentaram especificamente algum dado histórico, e os que afirmaram que não foi abordado em aula (e por isso não sabem), foram considerados como "Não", além dos que deixaram a questão em branco. Essas categorias foram criadas para distinguir bem os estudantes que apresentaram uma resposta negativa à questão, pois, em algumas de suas respostas, não se limitaram a responder apenas "não". A negação era acompanhada de uma justificativa. A Tabela 1 apresenta um resumo comparativo da etapa de pré-análise das respostas entre pré e pós-teste.

Tabela 1 - Conhecimento histórico

\begin{tabular}{c|c|c}
\hline \multicolumn{3}{c}{ Pré-teste 49 estudantes } \\
\hline Respostas & Total & Total (\%) \\
\hline Sim & 12 & 24,5 \\
\hline Não & 35 & 71,4 \\
\hline Não responderam Pós-teste 31 estudantes \\
\hline Respostas & 2 & 4,1 \\
\hline Sim & 17 & Total (\%) \\
\hline Não & 3 & 54,9 \\
\hline Não responderam & 11 & 9,6 \\
\hline
\end{tabular}

Fonte: Elaborada pelos autores (2019). 
Partindo para as etapas de exploração do material e tratamento dos resultados, foram selecionados os comentários de cinco estudantes para análise (Quadro 1).

Quadro 1 - Comentários dos estudantes sobre conhecimento histórico

\begin{tabular}{|c|c|}
\hline \multicolumn{2}{|r|}{ Pré-teste } \\
\hline Estudante 4 & [...]conheço sobre a Talidomida, onde o efeito colateral foi maior que o benefício. \\
\hline \begin{tabular}{|l|} 
Estudante 9 \\
\end{tabular} & O fato mais marcante foi um medicamento, onde um dos seus isômeros era maléfico [...]. \\
\hline Estudante 10 & $\begin{array}{l}\text { Lembro-me de um remédio que possuía um enantiômero que provocava malformação } \\
\text { em feto [...]. }\end{array}$ \\
\hline Estudante 14 & [...] fatos do remédio Talidomida desenvolvidos em uma mistura racêmica. \\
\hline Estudante 17 & $\begin{array}{l}\text { [...] depois de já descoberta a existência dos isômeros (R e S), ocorreu um problema com } \\
\text { a manipulação de um remédio, que era vendido em misturas racêmicas ( } \mathrm{R} \text { e } \mathrm{S} \text { juntos), } \\
\text { porém um deles tinha efeitos que faziam com que os bebês das grávidas que o ingerissem } \\
\text { nascessem deformados. }\end{array}$ \\
\hline \multicolumn{2}{|r|}{ Pós-teste } \\
\hline Estudante 4 & $\begin{array}{l}\text { [...]li essa parte sem prestar atenção, pois a história para mim sempre se apresenta de um } \\
\text { modo chato, sem atrativos e muitas vezes maçante [...]. }\end{array}$ \\
\hline Estudante 9 & $\begin{array}{l}\text { Podemos citar Wohler e Berzelius. Na história mostra que muitos cientistas não } \\
\text { acreditavam na hipótese de uma molécula ter uma geometria diferente no espaço, até } \\
\text { que Wöhler prova o contrário [...]. }\end{array}$ \\
\hline Estudante 10 & $\begin{array}{l}\text { [...] logo que o primeiro cientista propôs a ideia de existirem moléculas com diferentes } \\
\text { arranjos tridimensionais, foi alvo de críticas pela sociedade científica da época, que } \\
\text { achava isso uma loucura. }\end{array}$ \\
\hline Estudante 14 & $\begin{array}{l}\text { Podemos através do projeto (Unidade de Ensino) observar e aprender mais sobre a história } \\
\text { principalmente [...] onde os primeiros fatos sobre as descobertas foram recebidos com } \\
\text { descrédito, ganhando ao longo do tempo cada vez mais espaço, como as descobertas dos } \\
\text { desvios de luz polarizada, o uso de misturas racêmicas, etc. }\end{array}$ \\
\hline Estudante 17 & $\begin{array}{l}\text { No início acreditava-se que as estruturas reais das moléculas eram planas, sem 'medidas' } \\
\text { tridimensionais. Isso foi quebrado graças a um cientista alemão, o qual determinou e } \\
\text { descobriu a existência de duas moléculas e substâncias diferentes, as quais apresentavam } \\
\text { a mesma fórmula molecular, sendo diferenciadas entre si pelo arranjo espacial de seus } \\
\text { átomos. }\end{array}$ \\
\hline
\end{tabular}

Fonte: Elaborado pelos autores (2019).

Entre os 49 estudantes que participaram do pré-teste, apenas $12(24,5 \%)$ afirmaram conhecer algum fato histórico sobre o desenvolvimento da estereoquímica. Todos citaram, de alguma forma, apenas o caso da Talidomida, ocorrido em meados de 1960, sendo que o termo "isômero" foi criado pelo químico sueco Berzelius por volta de 1830 (ESTEBAN, 2008). Percebe-se claramente uma lacuna na contextualização histórica, haja vista que os estudantes investigados não têm conhecimento sobre as ideias, teorias e esforços da comunidade científica para o desenvolvimento da área (GONZÁLES, 2004).

Dos cinco estudantes analisados e apresentados no Quadro 1, apenas três citaram o nome do fármaco, e somente dois comentaram especificamente o problema que a Talidomida causou. O que sugere que essa informação, durante o ensino do tema, provavelmente foi abordada de forma superficial, resultando em comentários que meramente abordam que devido a algum medicamento que possuía um "isômero maléfico" houve o dano, a tragédia. É como se a Talidomida fosse o único fármaco com essa característica. Não podemos, no entanto, resumir toda estereoquímica a um fato apenas, pois a quiralidade é qualidade peculiar que compartilha muitas moléculas biologicamente importantes (BAGATIN et al., 2005), estando relacionada com o efeito farmacoló- 
gico de vários fármacos. Obviamente, em função das complicações advindas de seu uso, tornou-se o caso mais clássico e mais citado nos livros didáticos e consequentemente nas aulas de Química Orgânica.

Os fármacos enantioméricos na sua maioria não são sintetizados de forma enantioseletiva, o que leva à formação de ambos os enantiômeros (ROMERO, 1998). Por essa razão a lupac recomenda uma nomenclatura específica para os casos em que dois enantiômeros possuem potência de ação diferente. O enantiômero de maior ação farmacológica e afinidade pelo receptor é denominado eutômero, enquanto o outro, responsável pelo efeito indesejado, é denominado distômero (ORLANDO, 2007).

$\mathrm{Na}$ análise do pós-teste, 17 estudantes (54,9\%) afirmaram conhecer ao menos algum aspecto da história da estereoquímica e fazem uma breve explanação, conforme os comentários do Quadro 1. Houve destaque para o início do desenvolvimento da área, que foi apresentado na unidade de ensino. Os estudantes 10,14 e 17 destacam o papel dos cientistas, e o estudante 9 cita especificamente o nome de dois cientistas da área, Wöhler e Berzelius. Como relatado anteriormente, por volta de 1820, Friedrich Wöhler e Justus von Liebig, trabalhando separadamente, em seus respectivos laboratórios, sintetizaram dois compostos com propriedades distintas, mas que surpreendentemente apresentaram a mesma constituição química.

Os estudantes destacam também o episódio de descrença da comunidade científica na constatação do fenômeno isomeria, isso por que o paradigma estabelecido até então defendia que existia uma relação estrita entre a composição de uma substância e suas propriedades. Esses quatro estudantes apresentaram no pós-teste uma descrição rica em detalhes, o que evidencia a compreensão de como os cientistas trabalharam e a noção da evolução histórica. O estudante 4, no entanto, não comenta nenhum fato e afirma não ter interesse nos aspectos históricos apresentados. Essa afirmação evidencia que a forma como a história da ciência é abordada em aula é fundamental para ser considerada um elemento motivacional na aprendizagem. Assim, percebe-se uma necessidade de discussão sobre o sentido do contextualizar em sala de aula. De uma forma geral, é uma abordagem considerada simples de ser incorporada à prática docente. "Contudo, alguns trabalhos de pesquisa apontam que esse axioma não existe" (WARTHA; SILVA; BEJARANO, 2013, p. 84). Cabe destacar que a história da ciência precisa ser abordada de uma forma diferente de alguns livros didáticos que apresentam a história como apenas "uma sequência cronológica de eventos que somente está em um determinado capítulo por que é o tema da aula" (ORTIZ; PASSOS; DA SILVA, 2016, p. 124). De acordo com Leite (2002), deve-se buscar uma abordagem que proporcione aos estudantes uma ideia adequada sobre a natureza da ciência, a forma como ela se desenvolve e de como os cientistas trabalham, apresentando evolução histórica real, substituindo narrativas descontextualizadas que atribuem a um único cientista ou fato isolado todo desenvolvimento e sucesso de uma disciplina inteira (DO PRADO; CARNEIRO, 2018).

A segunda questão do teste (Tabela 2) tinha por objetivo investigar qual o nível de conhecimento dos estudantes sobre as aplicações e/ou presença da estereoquímica em seu cotidiano. 
Tabela 2 - Pré-teste

\begin{tabular}{l|c|c}
\hline \multicolumn{3}{c}{ Pré-teste 49 estudantes } \\
\hline Resposta & 18 & Total (\%) \\
\hline Não & 31 & 36,73 \\
\hline Sim (apenas fármacos) & 0 & 63,27 \\
\hline Sim (outros exemplos) & & 0 \\
\hline \multicolumn{2}{c}{ Pós-teste 31 estudantes } \\
\hline Resposta & 1 & Total (\%) \\
\hline Não lembram & 10 & 3,22 \\
\hline Sim (apenas fármacos) & 20 & 32,26 \\
\hline Sim (outros exemplos) &
\end{tabular}

Fonte: Elaborada pelos autores (2019).

No pré-teste, dos 49 estudantes participantes, 14 afirmaram não saber ou não conhecer nenhum exemplo, 4 afirmaram não se lembrar de nenhuma aplicação no cotidiano e 31 citaram a presença de estereoisômeros unicamente na indústria farmacêutica. Os resultados revelam um problema relatado por pesquisadores da área de ensino: uma compreensão da estereoquímica baseada apenas em conceitos científicos, o que pode apontar para uma das causas das dificuldades de aprendizagem. Desenvolver a compreensão conceitual de fenômenos que não estão relacionados ao cotidiano dos estudantes e sem a devida contextualização está relacionada ao motivo de os estudantes não compreenderem os fenômenos (BERNARDELLI, 2014; GABEL, 1993).

Em contrapartida, no pós-teste (Quadro 2), as respostas, mais variadas e detalhadas foram agrupadas em três categorias de acordo com o contexto apresentado e o detalhamento da informação. Dos 31 estudantes, apenas 12 comentaram, de forma geral, a presença da estereoquímica na indústria farmacêutica, como é o caso dos estudantes 9,14 e 16, ao afirmarem a relevância do tema para a área farmacêutica, sem especificar ou exemplificar.

Quadro 2 - Comentários dos estudantes sobre estereoquímica no cotidiano

\begin{tabular}{|l|l|}
\hline \multicolumn{2}{|c|}{ Pós-testes } \\
\hline Estudante 16 & ...muitos remédios são feitos com a estereoquímica. \\
\hline Estudante 9 & $\begin{array}{l}\text {...a farmácia utiliza-se bastante da estereoquímica na produção } \\
\text { dos medicamentos. }\end{array}$ \\
\hline Estudante 14 & $\begin{array}{l}\text {...há inúmeros remédios que utilizam estereoisômeros na sua } \\
\text { composição. }\end{array}$ \\
\hline Estudante 21 & paracetamol, ibuprofeno, ácido acetilsalicílico são alguns exemplos. \\
\hline Estudante 27 & $\begin{array}{l}\text {...nos remédios paracetamol existem enantiômeros, mas um deles } \\
\text { não tem efeito, pois é anulado. }\end{array}$ \\
\hline Estudante 4 & $\begin{array}{l}\text {...conheci o caso da 'Geração Talidomida' e quando estudei a } \\
\text { matéria tive um melhor entendimento [...] fiquei muito interessada } \\
\text { com o fato de compostos enantiômeros terem propriedades tão } \\
\text { distintas e causar efeitos tão adversos. }\end{array}$ \\
\hline Estudante 22 & $\begin{array}{l}\text { Não que ainda faça tanta parte do nosso dia a dia, mas, nos anos 60, } \\
\text { no Brasil, e nos anos 70, na Alemanha, foi feito um medicamento } \\
\text { com mistura racêmica contra enjoos. O remédio fez muito sucesso } \\
\text { entre as grávidas, mas o que não sabiam era que seus bebês nasciam } \\
\text { deficientes, era uma consequência de um dos enantiômeros do } \\
\text { composto orgânico, enquanto o outro aliviava os sintomas da gravidez. }\end{array}$ \\
\hline
\end{tabular}

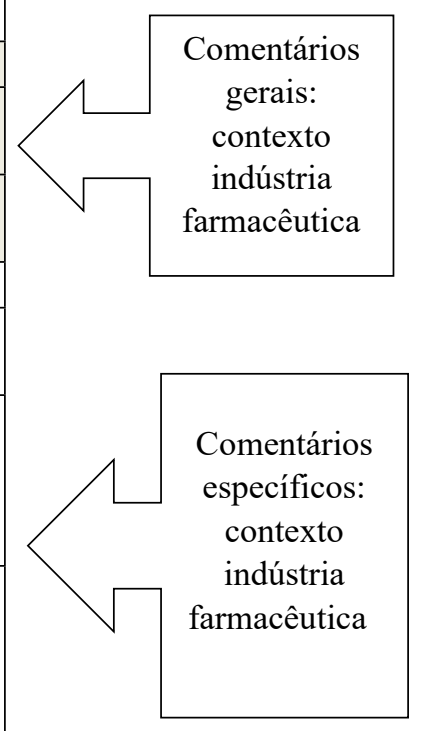




\begin{tabular}{|l|l|}
\hline Estudante 1 & ...o da laranja e limão, onde as moléculas destes são isômeros. \\
\hline Estudante 8 & $\begin{array}{l}\text {...alguns aromatizantes, como limão e laranja, são isômeros que } \\
\text { fazem parte do nosso cotidiano. }\end{array}$ \\
\hline Estudante 13 & O aspartame pode ser amargo e doce, dependendo do isômero... \\
\hline Estudante 5 & $\begin{array}{l}\text {...está presente nos medicamentos, no sabor de alguns alimentos, } \\
\text { na gordura trans e no caso da geração talidomida. }\end{array}$ \\
\hline Estudante 26 & $\begin{array}{l}\text {...a partir do material descobri que até em plantas isso interfere, } \\
\text { por exemplo, em algumas espécies de trepadeiras isso indica para } \\
\text { que lado ela irá se enroscar. }\end{array}$ \\
\hline
\end{tabular}

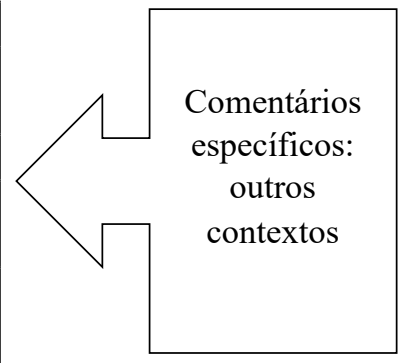

Fonte: Elaborado pelos autores (2019).

Nesse ponto percebe-se que um dos problemas, relacionados ao desenvolvimento desse campo, refere-se ao primeiro componente da tríade de um conceito: a situação. 0 processo de conceitualização é facilitado pelo uso das situações, como citado anteriormente: um conceito torna-se significativo por meio de uma variedade de situações e de diferentes aspectos de um mesmo conceito. Variedade que não foi evidenciada durante o pré-teste, no qual a única situação referente identificada pelos estudantes foi o caso da Talidomida, o que significa que o conhecimento está associado a uma única aplicação, o que, segundo Vergnaud, não seria suficiente para tornar o assunto significativo. Percebe-se que, com o uso da unidade, houve uma mudança tanto no padrão de respostas que pode ser considerada um indicativo de que estudantes compreenderam o desenvolvimento da estereoquímica, quanto um aumento em seu repertório de situação, como o nível de compreensão de suas aplicações, conforme discutido nas categorias a seguir.

\section{Comentários gerais: contexto indústria farmacêutica}

Nos comentários gerais sobre a indústria farmacêutica, percebe-se com o relato do estudante 16 ao afirmar que [...]muitos remédios são feitos com a estereoquímica, e do estudante 21 , ao citar os nomes dos medicamentos paracetamol, ibuprofeno, que existe a compreensão de que não é apenas um medicamento que possui essas características, mas sim uma série deles.

Destaca-se ainda que o isômero pode não ter efeito algum: "[...]nos remédios paracetamol existem enantiômeros, mas um deles não tem efeito, pois é anulado" (Estudante 27). Essa afirmação revela a compreensão do aluno acerca do comportamento dos enantiômeros, que dependendo do caso não necessariamente vão ter um efeito indesejado, como no caso da Talidomida. Entende-se que essa relação é característica devido à ampla gama de compostos orgânicos utilizados pelas indústrias desse ramo e pelo conhecimento prévio dos estudantes, no entanto a estereoquímica está presente em diversos segmentos e não se pode resumi-la apenas à sua importância no desenvolvimento de fármacos.

\section{Comentários específicos: contexto indústria farmacêutica}

A Talidomida, mencionada no pré-teste, também foi citada no pós-teste, com a diferença de que, no segundo caso, houve uma explanação mais elaborada sobre o caso, com maior riqueza de detalhes, como o caso do estudante 22, que apresenta uma detalhada explanação com aspectos históricos, identificando datas, países e o contexto do problema. 
A razão específica para esta inferência é que, entre o pré e o pós-teste, foi aplicada a intervenção didática que abordava exatamente os exemplos citados pelos estudantes no pós-teste e utilizados como evidenciado pela pesquisa. Assim "algo já conhecido torna-se muito mais significativo à medida que o conhecimento se expande em uma determinada especialidade" (BRAATHEN, 2012, p. 65). O teor dos comentários apresentados no pós-teste configuram-se como respostas mais sofisticadas, pois são mais elaborados e não se restringem apenas aos exemplos relacionados à área farmacêutica.

\section{Comentários específicos: outros contextos}

Diferentemente do pré-teste, os estudantes citam exemplos além do campo farmacêutico. $O$ estudante 1 comenta sobre os isômeros do limoneno, bem como o estudante 8 , que também destaca os mesmos isômeros e ressalta outros exemplos. 0 estudante 5 também comenta situações diferentes das relacionadas à área farmacêutica, além dos exemplos presentes na unidade de ensino sobre o sabor dos isômeros do aspartame e a gordura trans. O estudante 13 também comenta sobre as características relacionadas aos isômeros do aspartame. O estudante 26 afirma: "[...] que com a unidade conheceu situações diferentes relacionadas à estereoquímica, como no caso das trepadeiras que foi abordado na unidade".

Comparando os resultados antes e depois do uso da unidade de ensino, esses revelam que os conhecimentos históricos e contextuais estavam limitados a poucos exemplos quando os estudantes eram capazes de reconhecer fatos relacionados a esses campos. Nessa etapa, as questões foram direcionadas para que o aprendiz buscasse responder questões específicas de cada um dos aspectos da tríade de alfabetização proposta. Esses resultados com os estudantes reforçam as ideias presentes na revisão da literatura de que o ensino de Química é centrado na resolução de cálculos, aplicação de fórmulas, ênfase em nomenclatura e não privilegia os demais aspectos necessários para a motivação do estudante para a aprendizagem e para o domínio desse campo conceitual.

Após o uso do material elaborado, constata-se que os estudantes demonstraram ter assimilado outros exemplos de aplicação da estereoquímica, bem como detalhes relativos ao desenvolvimento e consolidação da área, permitindo constatar uma ampliação da variedade de situações, o que, segundo Vergnaud (1994), é uma das condições para que um conceito se torne significativo. Essa mudança evidencia a transformação do conteúdo abordado e não apenas uma mera repetição baseada na memorização de frases soltas. Por isso não podemos atribuir a mudança meramente ao viés de desvio de resposta de pré e pós-teste (já citado como uma das limitações do método). Na unidade de ensino foram abordados exemplos que não têm relação direta com os fármacos.

Por fim, as percepções dos estudantes sobre a unidade de ensino foram apuradas por meio da aplicação de um questionário de preenchimento facultativo, estruturado na escala Likert, em que os respondentes expressaram o nível de concordância com as afirmações cuja tabulação está apresentada na Tabela 3. 
Tabela 3 - Respostas dos estudantes quanto à unidade de ensino

\begin{tabular}{l|c|c|c|c|c}
\hline \multicolumn{1}{c|}{ Afirmações } & CP & C & NO & D & DT \\
\hline 1.Tenho a impressão de que aprendi bastante com essa unidade. & 4 & 31 & 5 & 2 & 0 \\
\hline 2. Eu não conhecia nenhum fato histórico relacionado à área. & 9 & 14 & 0 & 14 & 0 \\
\hline 3. Eu não conhecia nenhum fato relacionado ao cotidiano. & 3 & 8 & 0 & 21 & 10 \\
\hline $\begin{array}{l}\text { 4. A unidade de ensino permitiu que eu assimilasse melhor a teoria, } \\
\text { as ideias, os conceitos da estereoquímica. }\end{array}$ & 19 & 21 & 2 & 0 & 0 \\
\hline $\begin{array}{l}\text { 5. O texto fornece uma visão da evolução da estereoquímica como } \\
\text { ciência. }\end{array}$ & 21 & 18 & 3 & 0 & 0 \\
\hline
\end{tabular}

Legenda: CP: Concordo Plenamente; C: Concordo; NO: Indeciso/Não tenho opinião; D: Discordo; DT: Discordo Totalmente.

\section{Fonte: Elaborada pelos autores (2019).}

Sobre a opinião dos estudantes acerca do aprendizado com a unidade, nota-se que predominam a "concordância plena" ou "concordância" na questão 1. Quando questionados sobre o conhecimento histórico da área (questão 2), ao se cruzar os dados dessa questão com os dados do pré-teste (Tabela 1), percebe-se que $71,4 \%$ afirmam não ter conhecimento histórico, porém os estudantes que responderam ao pós-teste afirmam conhecer algum fato histórico. Esse fato se restringe ao episódio da Talidomida.

Essa questão, de um único exemplo aparecer tão repetidamente na fala dos estudantes, pode ser relacionada com o fato de este episódio ser o que comumente está presente nos livros didáticos e está alinhada com a afirmação de Fernandes e Porto (2012) de que algumas ideias são pinçadas e os autores apresentam nos livros, muitas vezes, a história mais como curiosidade e ilustração, restringindo-se a dados biográficos de cientistas e simples menções a ideias e descobertas. Uma simples menção revela superficialidade quanto à informação histórica (RAUPP, 2015). Esse é um ponto importante, pois o conhecimento sobre a história da ciência dá aos estudantes a oportunidade de ver como o conhecimento científico é provisório, assim eles estarão menos inclinados a ver a ciência como um livro de receitas e mais capazes de refletir sobre a complexidade e emoção de trabalho científico (LIND, 1980; GRIESEMER, 1985). A História promove melhor compreensão dos conceitos científicos e é intrinsecamente valiosa. Episódios importantes como a revolução científica, o darwinismo, a descoberta da penicilina, por exemplo, deveriam ser familiares a todo estudante (MATTHEWS, 1995). Naturalmente, uma visão absolutista da ciência ainda permeia insistentemente o sistema de ensino.

A respeito da falta de conhecimento sobre as aplicações práticas da estereoquímica (questão 3), nota-se que predominam a discordância ou a discordância total. Ao se cruzar os dados dessa questão com os dados do pré-teste (Tabela 2), percebe-se que, quando questionados sobre o conhecimento das aplicações antes da leitura da unidade no pré-teste, $63,24 \%$ afirmaram conhecer fatos relacionados, porém esses se limitavam a fatos que estavam relacionados apenas aos fármacos em geral e mais especificamente ao caso da Talidomida. Esse exemplo mostra que o conhecimento químico apresenta-se desvinculado do contexto social, quando esses deveriam estar inter-relacionados (SCHNETZLER; DOS SANTOS, 1997). 
Com a questão 4 objetivou-se entender se a unidade auxiliou na compreensão do campo da estereoquímica. A forma como o conteúdo foi apresentado na unidade de ensino, contemplando os aspectos históricos e contextuais, permitiu uma melhor compreensão da teoria, de acordo com 40 estudantes. Dessa maneira, espera-se que a compreensão do campo conceitual ocorra em seu significado mais amplo: um conjunto informal e heterogêneo de problemas, situações, conceitos, relações, estruturas, conteúdos e operações de pensamento, conectados uns aos outros e, provavelmente, entrelaçados durante o processo de aquisição (VERGNAUD, 1982). Na quinta questão analisada, um total de 39 estudantes concorda que o texto fornece uma visão da evolução da estereoquímica como ciência. Apesar de haver uma lacuna na relação química e realidade do estudante, em geral provocada por um profundo detalhamento conceitual, sem grande preocupação (CARDOSO; COLINVAUX, 2000), os estudantes mostram interesse em aprofundar seus conhecimentos. De acordo com Vygostky (1998), o desenvolvimento cognitivo não pode ser compreendido sem referência ao contexto histórico e cultural e sua ausência resultaria em um funcionamento intelectual limitado; a compreensão dos aspectos históricos e contextuais do campo da estereoquímica é fundamental para a mediação da aprendizagem, portanto. Essa concepção está em consonância com a TCC de Vergnaud (2007), que afirma que um conceito só se torna significativo para o indivíduo se ele consegue atribuir um sentido ao mesmo, ainda que a atribuição desse sentido esteja relacionada com seus esquemas.

\section{CONSIDERAÇÕES FINAIS}

A análise dos dados, inicialmente coletados, evidencia que o grupo de estudantes analisado demonstrou conhecimento superficial acerca das questões relacionadas à história e ao contexto da estereoquímica. Para ambos os aspectos foram citados basicamente o "famoso caso da Talidomida", resultado que, de certa forma, já era previsto, uma vez que a necessidade da contextualização do ensino de Química tem sido temática recorrente na área. Antes do uso da unidade de ensino - uma estratégia que privilegia uma compreensão mais ampla e não apenas restrita aos conceitos de classificação e nomenclatura - pode-se afirmar que os estudantes não possuíam o domínio de uma variedade de situações que tornassem o conceito significativo.

Assim sendo, buscou-se analisar a evolução dos alunos acerca dos aspectos históricos e contextuais da estereoquímica após a aplicação de uma unidade de ensino. Pode-se considerar que, para o grupo analisado, levando em conta as limitações de um estudo exploratório, em sua fase inicial, o uso de uma estratégia de ensino que utiliza uma abordagem histórica e contextual - com uma variedade de situações que perpassam as dimensões histórica, metodológica e socioambiental - motivou a aprendizagem e tem potencial para poder tornar mais eficiente o ensino e a aprendizagem da estereoquímica, uma vez que pode promover o aprendizado dos conceitos de forma mais abrangente.

Essa inferência é feita, pois, após o uso da unidade de ensino, os estudantes apresentaram um repertório bem mais variado de exemplos de situações, sendo capazes de identificar episódios da história e exemplos variados de aplicações ao cotidiano, explicando, com riqueza de detalhes, extrapolando os exemplos relacionados à indústria 
farmacêutica. O teor dos comentários dos estudantes também não é igual "ipsis litteris" ao que foi exposto na unidade de ensino, tratando-se, portanto, de uma transformação do conhecimento adquirido, uma vez que o aluno utilizou a informação discutida na unidade em diferentes situações e com sua própria linguagem. Considerando que, de acordo com a Teoria dos Campos Conceituais, o uso de situações e a identificação dessas no cotidiano do aluno traz um sentido ao conceito, acredita-se que a utilização de uma abordagem contextualizada pode colaborar para uma melhor compreensão do campo conceitual. E essa compreensão poderá contribuir para que os estudantes superem suas dificuldades específicas e tenham motivação para aprender o tema. Com o domínio de determinados aspectos desse campo, uma vez que as situações que envolvem a estereoquímica já farão parte de seus esquemas, espera-se que será menos traumático o desafio inerente de resolver problemas de ordem conceitual, como nomenclatura, por exemplo, bem como a resolução de problemas no nível tridimensional, para, assim, superar suas dificuldades exclusivas da área no que se refere aos conteúdos do Ensino Médio.

\section{REFERÊNCIAS}

ARICAN, Muhammet. Preservice Middle and High School Mathematics Teachers' Strategies when Solving Proportion Problems. International Journal of Science and Mathematics Education, v. 16, n. 2, p. 315-335, 2018. Disponível em: https://link.springer.com/article/10.1007/s10763-016-9775-1. Acesso em: 20 out. 2018.

BAGATIN, Olga; SIMPLÍCIO, Fernanda Ibanez; SANTIN; Silvana Maria de Oliveira; SANTIN FILHO, Ourides. Rotação de Luz Polarizada por Moléculas Quirais: abordagem histórica com proposta experimental. Química Nova na Escola, v. 21, p. 34-38, 2007. Disponível em: http://qnesc.sbq.org.br/online/qnesc21/ v21a07.pdf. Acesso em: 4 jun. 2019.

BARDIN, Laurence. Análise de conteúdo. Lisboa: Edições, 1977. V. 70.

BARRERA, Sylvia Domingos. Teorias cognitivas da motivação e sua relação com o desempenho escolar. Poiesis Pedagógica, v. 8, n. 2, p. 159-175, 2010. Disponível em: https://www.revistas.ufg.br/poiesis/article/view/14065. Acesso em: 20 out. 2018.

BHANJI, Farhan; GOTTESMAN, Ronald; DE GRAVE, Willem; STEINERT, Yvonne; WINER, Laura. The retrospective pre-post: A practical method to evaluate learning from an educational program. Academic Emergency Medicine, v.19, n. 2, p. 189-194, 2012.

BERNARDELLI, Marlize Spagolla. Encantar para ensinar - um procedimento alternativo para o ensino de química. In: CONVENÇÃO BRASIL-LATINO-AMÉRICA DE ENSINO. CONGRESSO BRASILEIRO E ENCONTRO PARANAENSE DE PSICOTERAPIAS CORPORAIS. 2014, Foz do Iguaçu. Anais eletrônicos [...]. Foz do Iguaçu: Centro Reichiano, 2014. Disponível em: http://www.centroreichiano.com.br/artigos/Anais-2004/BERNARDELLI-Marlize-Spagolla-Encantar.pdf. Acesso em: 20 out. 2018.

BRAATHEN, Per Christian. Aprendizagem mecânica e aprendizagem significativa no processo de ensino-aprendizagem de Química. Revista Eixo, v. 1, n. 1, p. 63-69, 2012.

BRASIL. Governo Provisório da República dos Estados Unidos do Brasil. Decreto no 19.890, de 18 de abril de 1931. Rio de Janeiro, 18 de abril de 1931. Disponível em: http://www.histedbr.fae.unicamp.br/navegando/fontes_escritas/5_Gov_Vargas/decreto\%2019.890-\%201931\%20reform. Acesso em: 20 out. 2018. BRASIL. Ministério da Educação; Secretaria da Educação Média e Tecnológica. Parâmetros Curriculares Nacionais: Ensino Médio. Brasília, 1999.

BRASIL. Ministério da Educação. Diretrizes Curriculares Nacionais para os Cursos de Química. Parecer № CNE/CES 1.303/2001, 2001.

BRASIL. Ministério da Educação. Diretrizes Curriculares Nacionais Gerais da Educação Básica, 2013.

BRASIL. Ministério da Educação. Base Nacional Comum Curricular, 2018.

BROOKS, Linda; GERSH, Tracey L. Assessing the Impact of Diversity Initiatives Using the Retrospective Pretest Design. Journal of College Student Development, v. 39, n. 4, p. 383-85, 1998.

BRUSH, Stephen G. Thomas Kuhn as a historian of science. Science e Education, v. 9, n. 1-2, p. 39-58, 2000. 
CÂMARA, Rosana Hoffman. Análise de conteúdo: da teoria à prática em pesquisas sociais aplicadas às organizações. Gerais: Revista Interinstitucional de Psicologia, v. 6, n. 2, p. 179-191, 2013.

CARDOSO, Sheila Pressentin; COLINVAUX, Dominique. Explorando a motivação para estudar química. Química Nova, v. 23, n. 3, p. 401-404, 2000. Disponível em: http://www.scielo.br/pdf/\%0D/qn/v23n3/2827. pdf. Acesso em: 20 out. 2018.

CARVALHO JÚNIOR, Gabriel Dias; AGUIAR JUNIOR, Orlando Gomes de. Os campos conceituais de Vergnaud como ferramenta para o planejamento didático. Caderno Brasileiro de Ensino de Física, v. 25, $\mathrm{n}$. 2, p. 207-227, 2008. Disponível em: https://periodicos.ufsc.br/index.php/fisica/article/view/2175-7941. 2008v25n2p207/5632. Acesso em: 20 out. 2018.

CHASSOT, Attico. Alfabetização científica: questões e desafios para a educação. 4. ed. ljuí: Editora Unijuí, 2000.

CHENG, Huai. N. et al. (ed.). Stereochemistry and Global Connectivity: The Legacy of Ernest L. Eliel. V. 2. American Chemical Society, 2017.

COELHO, Fernando A. S. Fármacos e quiralidade. Química Nova na Escola, n. 3, 2001. Disponível em: http://qnesc.sbq.org.br/online/cadernos/03/quiral.pdf. Acesso em: 20 out. 2018.

DAL-FARRA, Rossano André; LOPES, Paulo Tadeu Campos. Métodos mistos de pesquisa em educação: pressupostos teóricos. Nuances: Estudos sobre Educação, v. 24, n. 3, p. 67-80, 2013. Disponível em: http://revista.fct.unesp.br/index.php/Nuances/article/view/2698/2362. Acesso em: 20 out. 2018.

DAL-FARRA, Rossano André; FETTERS, Michael D. Recentes avanços nas pesquisas com métodos mistos: aplicações nas áreas de Educação e Ensino. Acta Scientiae, v. 19, n. 3, 2017. Disponível em: http://www. periodicos.ulbra.br/index.php/acta/article/view/3116/2368. Acesso em: 20 out. 2018.

DA ROSA, Cleci Werner; DA ROSA, Álvaro Becker. O ensino de Ciências (Física) no Brasil: da história às novas orientações educacionais. Revista Iberoamericana de Educación, on-line, v. 52, p. 1-24, 2012. Disponível em: https://rieoei.org/RIE/article/view/1446. Acesso em: 10 set. 2018.

DE ANDRADE, Lucia Machado; HONÓRIO, Káthia Maria; BUENO FILHO, Marco Antonio. Collective action and collective scheme in the mobilization of learning chemistry according to Vergnaud's theory of conceptual fields. Problems of Education in the 21st Century, v. 75, n. 5, 2017. Disponível em: http://www.scientiasocialis.It/pec/node/files/pdf/vol75/419-433.Andrade_Vol.75-5_PEC.pdf. Acesso em: 20 out. 2018.

DE ARAÚJO, Denise Lino. O que é (e como faz) sequência didática? Entrepalavras, v. 3, n. 1, p. 322-334, 2013.

DE OLIVEIRA GRINGS, Edi Terezinha; MOREIRA, Marco Antonio; CABALLERO, Concesa. Significados dos conceitos da termodinâmica e possíveis indicadores de invariantes operatórios apresentados por estudantes do ensino médio e técnico. Revista Liberato, v. 8, n. 10, 2007. Disponível em: http://www.liberato. com.br/sites/default/files/arquivos/Revista_SIER/v.\%208\%2C\%20n.\%2010\%20\%282007\%29/1.\%20Significados\%20dos\%20conceitos\%20da\%20termodin\%E2mica\%20e\%20poss\%EDveis\%20indicadores.pdf. Acesso em: 20 out. 2018.

DO PRADO, Letícia; CARNEIRO, Marcelo Carbone. O episódio histórico das teorias do flogisto e calórico: criando interfaces entre a História e Filosofia da Ciência e o Ensino de Química na busca pela humanização do trabalho científico. História da Ciência e Ensino: Construindo Interfaces, v. 18, p. 153-180, 2018.

ESTEBAN, Soledad. Liebig-Wöhler Controversy and the Concept of Isomerism. Journal of Chemical Education, v. 85, n. 9, 2008.

EVANS, Gordon. Stereochemistry in the terminal course. Journal of Chemical Education, v. 40, 1963.

FERNANDES, Maria Angélica Moreira; PORTO, Paulo Alves. Investigando a presença da história da ciência em livros didáticos de química geral para o ensino superior. Química Nova, v. 35, n. 2, p. 420-429, 2012.

FROMM, F. On stereochemistry. Journal of Chemical Education, (Letter), v. 1, p. 4.322, 1945.

GABEL, Doroty. Use of the particle nature of matter in developing conceptual understanding. Journal of Chemical Education, v. 70, n. 3, p. 193-194, 1993.

GASTALDO, Luís Fernando. Módulos didáticos hipermídicos para o ensino de eletromagnetismo e óptica no ensino médio. SIMPÓSIO NACIONAL DE ENSINO DE FÍSICA, 17., 2007, São Luís: Sociedade Brasileira de Física, 2007.

GILBERT, John K. (ed.). Visualization in Science Education, Dordrecht: Springer, 2005. 346 p.

GONZÁLEZ, Carlos Vázquez. Reflexiones y Ejemplos de Situaciones Didácticas para una Adecuada Contextualización de los Contenidos Científicos en el Proceso de Enseñanza. Revista Eureka sobre Enseñanza y Divulgación de las Ciencias, v. 1, n. 3, 2004. Disponível em: http://www.redalyc.org/pdf/920/92001306. pdf. Acesso em: 20 out. 2018.

GRAHAM SOLOMONS, T. W. FRYHLE, Craig B. Química orgânica, Rio de Janeiro: LTC, v. 17, 492 p., 2001. 
GRIESEMER, Jim. Philosophy of Science and" The" Scientific Method. The American Biology Teacher, v. 47, n. 4, p. 211-215, 1985. Disponível em: http://abt.ucpress.edu/content/47/4/211.full.pdf+html. Acesso em: 20 out. 2018.

HABRAKEN, Clarisse L. Perceptions of chemistry: Why is the common perception of chemistry, the most visual of sciences so distorted? Journal of Science Education and Technology, Amsterdam, v. 5, n. 3, p. 193-201, 1996.

HARGITTAI, Balazs; HARGITTAI, István. Nobel Prize and structural chemistry II. 2012. Disponível em: https://link.springer.com/content/pdf/10.1007\%2Fs11224-011-9932-7.pdf.

HARRIS, Victor; VISCONTI, Brian, SENGUPTA, Prami; HINTON, Ginny. Justification for Use of the PreTest then Retrospective Pre-then-Post-Test Evaluation in Couple and Relationship Education. Southeastern Council on Family Relations 2018 Conference, Louisiana, 2018.

HELLER, Agnes. Cotidiano e história. Rio de Janeiro: Paz \& Terra, 1989.

HOWARD, George S.; DAILEY, Patrick R. Response-shift bias: A source of contamination of self-report measures. Journal of Applied Psychology, v. 64, n. 2, p. 144, 1979.

KAPLAN, David. The Sage handbook of quantitative methodology for the social sciences. Thousand Oaks, CA: Sag, 2004. 511 p.

KURZER, F. Fulminic acid in the history of organic chemistry. Journal of Chemical Education, v. 77, n. 7, p. 851, 2000.

LEHNINGER, Albert. L.; NELSON, David. L. Princípios de bioquímica. New York: Sarvier, 1995.

LEITE, Laurinda. History of science in science education: development and validation of a checklist for analysing the historical content of science textbooks. Science e Education, Dordrecht, v. 11, n. 4, p. 333359, 2002. Disponível em: https://link.springer.com/content/pdf/10.1023\%2FA\%3A1016063432662.pdf. Acesso em: 14 abr. 2018.

LEITE, Helena S. A; PORTO, P. Análise da abordagem histórica para a Tabela Periódica em livros de Química Geral para o Ensino Superior usados no Brasil no século XX. Química Nova, v. 38, n. 4, p. 580-507, 2015.

LIMA, Josária; PINA, Maria do Socorro; BARBOSA, Rejane; JÓFILI, Zélia. Contextualização no ensino de Cinética Química. Química Nova na Escola, n. 11, p. 26-29, 2000. Disponível em: http://qnesc.sbq.org.br/ online/qnesc11/v11a06.pdf. Acesso em: 25 set. 2018.

LIND, Gunter. Models in physics: Some pedagogical reflections based on the history of science. European Journal of Science Education, v. 2, n. 1, p. 15-23, 1980. Disponível em: https://link.springer.com/content/ pdf/10.1023\%2FA\%3A1016063432662.pdf. Acesso em: 23 out. 2018.

LOGUERCIO, Rochele.; DEL PINO, José Cláudio. Livros didáticos: mais que uma simples escolha, uma decisão que pode orientar os trabalhos em sala de aula. 1995. Disponível em: http://www.iq.ufrgs.br/aeq/ producao/delpino/analise_livros.pdf. Acesso em: 16 abr. 2018.

MATTHEWS, Michael. História, Filosofia e Ensino de Ciências: a tendência atual de reaproximação. Caderno Catarinense de Ensino de Física, Florianópolis, v. 12, n. 3, p. 164-214, 1995. Disponível em: https:// periodicos.ufsc.br/index.php/fisica/article/view/7084. Acesso em: 15 set. 2018.

MOREIRA, Marco Antônio. A teoria dos campos conceituais de Vergnaud, o ensino de ciências e a pesquisa nesta área. Investigações em Ensino de Ciências, Porto Alegre, v. 7, n. 1, p. 7-29, 2002. Disponível em: https://www.if.ufrgs.br/cref/ojs/index.php/ienci/article/download/569/361. Acesso em: 10 out. 2018.

MORTIMER, Eduardo Fleury; MACHADO, Andréa Horta; ROMANELLI, Lilavate Izapovitz. A proposta curricular de Química do Estado de Minas Gerais: fundamentos e pressupostos. Química Nova, v. 23, n. 2, p. 273-281, 2000. Disponível em: http://www.scielo.br/pdf/qn/v23n2/2131.pdf. Acesso em: 15 set. 2018.

NÍAZ, Mansoor. A Rational Reconstruction of the Kinetic Molecular Theory of Gases Based on History and Philosophy of Science and its Implications for Chemistry Textbooks. Instructional Science, v. 28, n. 1, p 23-50, 2000. Disponível em: https://link.springer.com/content/pdf/10.1023\%2FA\%3A1003429101358. pdf. Acesso em: 18 set. 2018.

ORLANDO, Ricardo Mathias. Importância farmacêutica de fármacos quirais. Revista Eletrônica de Farmácia, v. 4, n. 1, 2007. Disponível em: https://doi.org/10.5216/ref.v4i1.2115. Acesso em: 4 jun. 2019.

ORTIZ, Etiane; PASSOS, Marinez Meneghello; DA SILVA, Marcos Rodrigues. Investigando o que estudantes do curso de Ciências Biológicas pensam a respeito da história da ciência. Revista Contexto \& Educação, Ijuí: Editora Unijuí, v. 30, n. 97, p. 117-137, 2016. Disponível em: https://www.revistas.unijui.edu.br/index.php/contextoeducacao/article/download/3216/4964.Acesso em: 11 set. 2018.

PANTOJA, Glauco Cohen; MOREIRA, Marco Antonio. A potentially meaningful teaching unit for the teaching of the concept of field in Physics. Latin-American Journal of Physics Education, v. 11, n. 1, p. 2, 2017. Disponível em: http://www.lajpe.org/mar17/1302_Glauco_2017.pdf. Acesso em: 11 set. 2018. 
POZO, Juan Ignacio. Aprendizes e mestres: a nova cultura da aprendizagem. Porto Alegre: Artmed, 2002. $296 \mathrm{p}$.

PRATT, Clara C.; MCGUIGAN, William M.; KATZEV, Aphra R. Measuring program outcomes: Using retrospective pretest methodology. American Journal of Evaluation, v. 21, n. 3, p. 341-349, 2000.

PRODANOV, Cleber Cristiano; FREITAS, Ernani Cesar de. Metodologia do trabalho científico: métodos e técnicas da pesquisa e do trabalho acadêmico. Novo Hamburgo: Feevale, 2013.

RAUPP, Daniele Trajano; DEL PINO, José Cláudio. Estereoquímica no Ensino Superior: historicidade e contextualização em livros didáticos de Química Orgânica. Acta Scientiae, v. 17, n. 1, 2015.

RAUPP, Daniele Trajano. Alfabetização tridimensional, contextualizada e histórica no campo conceitual da estereoquímica. 2018. Tese (Doutorado em Educação em Ciências. PPGQVS - Universidade Federal do Rio Grande do Sul. 2015. Disponível em: https://lume.ufrgs.br/handle/10183/122337. Acesso em: 30 set. 2018.

REBELLO, Sanjay; CUI, Lili; BENNETT, Andrew; ZOLLMAN, Dean. A.; OZIMEK, Darryl J. Transfer of learning in problem solving in the context of mathematics and physics. Learning to solve complex scientific problems, 2007. p. 223-246. Disponível em: https://perg.phys.ksu.edu/papers/2006/TransferInProblemSolving-FullChapter-v32.pdf. Acesso em: 11 set. 2018.

ROMERO, José Ricardo. Fundamentos de estereoquímica dos compostos orgânicos. [S.I]: Holos Editora, 1998. 108 p.

SANTOS, Wildson; MORTIMER, Eduardo Fleury. A dimensão social do ensino de Química - um estudo exploratório da visão de professores. ENCONTRO NACIONAL DE PESQUISA EM EDUCAÇÃO EM CIÊNCIAS, 2., 1999, Valinhos. Anais eletrônicos [...]. Valinhos, 1999. Disponível em: http://fep.if.usp.br/ profis/arquivos/iienpec/Dados/trabalhos/A57.pdf. Acesso em: 10 set. 2018.

SCHMIEDECKE, Winston Gomes; PORTO, Paulo Alves. A história da ciência e a divulgação científica na TV: subsídios teóricos para uma abordagem crítica dessa aproximação no ensino de ciências. Revista Brasileira de Pesquisa em Educação em Ciências, v. 15, n. 3, p. 627-643, 2015.

SCHNETZLER, Roseli Pacheco; DOS SANTOS, Wildson Luiz Pereira. Educação em Química: compromisso com a cidadania. Ijuí: Ed. Unijuí, 1997.

SHINE, Henry. Aids in teaching stereochemistry: Plastic sheets for plane projection diagrams. Journal of Chemical Education, v. 34, n. 7, p. 355, 1957.

SILVA, Airton Marques; SILVA, Wendel Jerônimo (UECE). Dificuldades de aprendizagem no ensino de isomeria para estudantes do Ensino Médio. In: CONGRESSO BRASILEIRO DE QUÍMICA, 47., Área: Ensino de Química. 2007, Natal. Anais eletrônicos [...]. Natal, 2007. Disponível em: http://www.abq.org.br/ cbq/2007/trabalhos/6/6-294-521.htm. Acesso em: 20 out. 2018.

SILVA SOUZA, Penha; LEITE, Laurinda. A contextualização e os princípios orientadores da educação do campo nos materiais didáticos da área das ciências da vida e da natureza. In: CONGRESSO IBERO-AMERICANO DE DOCÊNCIA UNIVERSITÁRIA, 9., Universidad de Murcia. Servicio de Publicaciones, 2016, p. 669673. Disponível em: https://repositorium.sdum.uminho.pt/handle/1822/42300. Acesso em: 20 out. 2018. STOCKLMAYER, Susan M.; TREAGUST, David F. A Historical Analysis of Electric Currents in Textbooks: A Century of Influence on Physics Education. Science \& Education, v. 3, n. 2, p. 131-154, 1994. Disponível em: https://link.springer.com/content/pdf/10.1007\%2FBF00486388.pdf. Acesso em: 20 out. 2018.

TAPIA, Jesus Alonso; FITA, Enrique Caturla. O professor e a motivação dos estudantes. In: TAPIA, J. A.; FITA, E. C. A motivação em sala de aula: o que é, como se faz. 4. ed. São Paulo: Loyola, 1999. p. 65-135.

VERGNAUD, Gérard. A classification of cognitive tasks and operations of thought involved in addition and subtraction problems. In: CARPENTER, T.; MOSER, J.; ROMBERG, T. Addition and subtraction. A cognitive perspective. Hillsdale: Lawrence Erlbaum, 1982. p. 39-59.

VERGNAUD, Gérard. Multiplicative conceptual field: what and why? In: GUERSHON, H.; CONFREY, J. (ed.). The development of multiplicative reasoning in the learning of mathematics. Albany: State University of New York Press, 1994. p. 41-59.

VERGNAUD, Gérard. Education: the best part of Piaget's heritage. Swiss Journal of Psychology, Bern, v. 55, n. 2/3, p. 112-118, 1996 .

VERGNAUD, Gérard. A trama dos campos conceituais na construção dos conhecimentos. Revista do Gempa, Porto Alegre, n. 4, p. 9-19, 1996 b.

VERGNAUD, Gérard. Comprehensive theory of representation for Mathematics Education. Journal of Mathematical Behavior, v. 2, n. 17, p. 167-181, 1998.

VERGNAUD, Gérard. Représentation et activité: deux concepts étroitement associés. Recherches en Éducation, v. 4, p. 9-22, 2007. 


\section{\& Contexto}

VERGNAUD, Gerard et al. Teoria dos campos conceituais. SEMINÁRIO INTERNACIONAL DE EDUCAÇÃO MATEMÁTICA, 1., Rio de Janeiro, 1993. Anais [...]. Rio de Janeiro, 1993. p. 1-26.

VILCHES, Amparo; SOBES, Jordi. La introducción de las relaciones Ciencia, Tecnología y Sociedad en la enseñanza de las ciencias y su evolución. Educación Química, v. 11, n. 4, p. 387-394, 2000. Disponível em: http://revistas.unam.mx/index.php/req/article/view/66432/58318. Acesso em: 20 out. 2018.

VYGOTSKY, Lev Semyonovich. A formação social da mente. São Paulo: Martins Fontes, 1998. 191 p.

WARTHA, Edson José; SILVA, E. L da; BEJARANO, Nelson Rui Ribas. Cotidiano e contextualização no ensino de Química. Química Nova na Escola, v. 35, n. 2, p. 84-91, 2013. Disponível em: http://qnesc.sbq.org.br/ online/qnesc35_2/04-CCD-151-12.pdf. Acesso em: 20 out.

WU, Hsin Kai; SHAH, Priti. Exploring visuospatial thinking in chemistry learning. Science Education, v. 88, n. 3, p. 465-492, 2004. Disponível em: https://onlinelibrary.wiley.com/doi/epdf/10.1002/sce.10126. Acesso em: 22 out. 